Industrial Health, 1977, 15, 59.

\title{
VIBRATION EFFECTS ON HAND-ARM-SYSTEM
}

\section{PART 2. OBSERVATION OF SKIN TEMPERATURE}

\author{
Tadayoshi SAKURAI \\ Department of Environmental Health, Medical School, Kurume \\ University, Asahi-machi, Kurume, Fukuoka 830 Japan
}

(Received May 9, 1977)

\begin{abstract}
Skin temperature at the third finger tip of left hand on the radial side was observed with a thermister. Vibration was given the left hand of a subject who gripped a handle set on a vibration table of electrodynamic type. The room temperature was varied at $22^{\circ} \mathrm{C}$ and $10^{\circ} \mathrm{C}$.

Effects of factors concerning the vibrations (magnitude, frequency, exposure time), gripping force and room temperatures on the skin temperature were studied by using the experimental design method. In the first experiment, for impressing large vibration magnitude over $50 \mathrm{~g}$, recovery of the skin temperature after stop of the vibration was slow as compared with the small vibration amplitude. In the second experiment, the recovery of the skin temperature was clearly retarded in the low room temperature $\left(10^{\circ} \mathrm{C}\right)$. This tendency especially was promoted on the longer vibration exposure time than the shorter one.
\end{abstract}

It was reported that on lpatients of the vibration diseases, organic or functional degenerations in hemodynamics were observed. ${ }^{1)}$ Their main causes had been considered to be abnormal state of the sympathetic nervous system including the vasomotor nerves.

The blood vessels of normal persons were contracted by start of exposure of the vibration, ${ }^{2)}$ or the cold, ${ }^{3)}$ or the sound ${ }^{4)}$ and then, the blood vessels were dilated as soon as stop of the stimulation. On the patients of the vibration disease, the dilatation of the blood vessels, however, was very slow since the stop of the stimulations. This symptom has been studied clinically as vasospastic syndroms on the vibration diseases.

In the present paper, the skin temperature of the hand was observed under the conditions that the vibration was given to the same hand of the subject who was asked to grip a handle set on the vibration table. Both conditions were tested, for example, one was to aim at the high amplitude vibration over $50 \mathrm{~g}$ in the wide frequency range in the normal room temperature, the other was the strong gripping force and the large amplitude vibration in the low frequency range in the low room temperature of $10^{\circ} \mathrm{C}$. 


\section{T. SAKURAI}

\section{Experimental Procedures}

Skin temperature was observed at the third finger tip on the radial side of the left hand of a subject with a thermister. The output signal of the thermister was continusously recorded by a pen-writing recorder (SANEI Co. $8 \mathrm{~s}$ ) through a Wheatstone bridge during the experiment. Time constant with regard to thermal capacity of the thermister was selected as $2 \mathrm{~s}$ enough to be able to follow the thermal phenomenon in our body.

Observation of the skin temperature was made simultaneously in experiments mentioned in Part 1, in which electromyogram was observed at the forearm. The first experiment was done in the room in which the room temperature was controlled at $22^{\circ} \mathrm{C}$. The second experiment was done in the temperature controlled room, in which the temperature was varied at $22^{\circ} \mathrm{C}$ or at $10^{\circ} \mathrm{C}$. On the low room temperature of $10^{\circ} \mathrm{C}$, the subject was permitted to wear the same thick overcoat except exposing his left forearm.

The factors tested with the experimental design method were the same as described in Part 1.

\section{Results AND Discussion}

In the present experiments, the skin temperature decreased continuously since start of gripping of the handle on the vibration table, during which the vibration was given at some part in the whole period of gripping. Then, the skin temperature increase as soon as stop of the gripping until recovering to the initial temperature. The former called a cooling process and the latter a recovery process.

This fact was already found out by Hettinger ${ }^{5)}$ who investigated the female stenotypist. Their fingers were exposed to the vibration for $30 \mathrm{~s}$ by a mechanical vibration table to examine the recovery process of skin temperature. He made Hettinger's equation for analysis of the recovery process, in which the recovery time was considered explicitly and called the skin temperature index. The equation was $(1+U / 1+V)(1+t / 4)$. In our experiments, the variables in this equation are arranged as follows, $U$; the difference of skin temperature measured at between start and stop of gripping of the handle, $V$; the difference of skin temperature between the maximum value in the recovery process and the value measured at stop of gripping, $t$; in the recovery process, the elapsed time from stop of the gripping to the time when the skin temperature is recovered to the initial temperature measured at start of the gripping. If the skin temperature was not recovered to the initial temperature, the time when the skin temperature reached the maximum value was read out. The skin temperature index means that its large value corresponds to the slow recovery of the skin temperature, that is, to retard of the dilatation in the peripheral blood vessels in the hand.

The variance analysis was calculated on the data of skin temperature index as shown 


\section{VIBRATION EFFECTS ON HAND-ARM-SYSTEM}

in Tables 1, a and 2, a. Averages and confidence limits at each level of the factors which indicate significance in the variance analysis are exhibited in Tables $1, \mathrm{~b}$ and $2, \mathrm{~b}$. In Tables 1, a and 2, a, the factor of vibration amplitude (B) shows significance in variance analysis. The larger amplitude of vibration (level 2) causes the larger values of skin temperature index than the other level of 1 . It is supposed that the vibration disturbs control of the vasomotor nerve and causes insufficient dilatation of the peripheral blood vessels so that the recovery of skin temperature may be retarded. This result is compared with the result examined in the preliminary experiment on 4 subjects, who gripped the handle on the vibration table with or without impressing the vibration. In the recovery process without the vibration the skin temperature swiftly recovered to the initial value, and moreover, overshooted beyond the initial value. In the recovery process with the vibration, the recovery delayed.

In the second experiment, the factor of the exposure time (A) is significant. The skin temperature is not varied as soon as change of blood flow owing to contraction or dilatation of the blood vessels, because of thermal capacity around the measuring part of the temperature. The vibration exposure time is not statistically significant in the first experiment in which the exposure time was not so long. The exposure time of the vibration in the second experiment causes the difference of the skin temperature between two levels of the exposure time in the recovery process.

Table 1, a. Variance analysis of skin temperature on the first experiment in which the vibration magnitude was very large and frequency was quite wide. $t$ is variance of the factor of repetition of the experiment $(\mathrm{H})$ and $\mathrm{T}$ is total variance.

\begin{tabular}{ccccc}
\hline Factor & SS & df & $\mathrm{F}((\mathrm{SS} / \mathrm{df}) /(\mathrm{SSe} / \mathrm{dfe}))$ & Test \\
\hline $\mathrm{A}$ & 0.041 & 1 & 0.76 & \\
$\mathrm{~B}$ & 0.323 & 1 & 6.03 & \\
$\mathrm{C}$ & 0.065 & 3 & 0.40 & \\
$\mathrm{t}$ & 0.333 & 3 & 2.07 & \\
$\mathrm{e}$ & 2.950 & 55 & & \\
\hline $\mathrm{T}$ & 3.712 & 63 & & \\
\hline
\end{tabular}

(次; $\mathrm{p}<0.05)$

Table 1, b. Means and confidence limits of the factors which are significance in the variance analysis. Effect means the difference between the two levels.

\begin{tabular}{|c|c|c|c|c|c|c|}
\hline \multirow{3}{*}{ Factor } & \multicolumn{6}{|c|}{ Level } \\
\hline & \multicolumn{2}{|r|}{1} & \multicolumn{2}{|r|}{2} & \multicolumn{2}{|c|}{ Effect } \\
\hline & Mean & $\begin{array}{c}\text { Confidence } \\
\text { limits }(95 \%)\end{array}$ & Mean & $\begin{array}{c}\text { Confidence } \\
\text { limits }(95 \%)\end{array}$ & Mean & $\begin{array}{c}\text { Confidence } \\
\text { limits }(95 \%)\end{array}$ \\
\hline B & 1.20 & \pm 0.08 & 1.34 & \pm 0.09 & 0.14 & \pm 0.12 \\
\hline
\end{tabular}




\section{T. SAKURAI}

Table 2, a. Variance analysis of skin temperature on the second experiment in which the room temperature was varied at $22^{\circ} \mathrm{C}$ and $10^{\circ} \mathrm{C}$.

\begin{tabular}{|c|c|c|c|c|}
\hline Factor & SS & $\mathrm{df}$ & $\mathrm{F}((\mathrm{SS} / \mathrm{df}) /(\mathrm{SSe} / \mathrm{dfe}))$ & Test \\
\hline A & 1.57 & 1 & 4.83 & $\sum$ \\
\hline $\mathrm{B}$ & 4.23 & 1 & 13.02 & 車放 \\
\hline $\mathrm{C}$ & 0.03 & 1 & 0.09 & \\
\hline $\mathrm{D}$ & 1.81 & 1 & 5.57 & 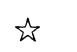 \\
\hline $\mathrm{E}$ & 1.36 & 1 & 4.18 & 象㐾 \\
\hline $\mathrm{F}$ & 4.96 & 1 & 15.26 & 论场 \\
\hline G & 1.70 & 1 & 5.23 & $\sum$ \\
\hline $\mathrm{H}$ & 0.46 & 1 & 1.42 & \\
\hline $\mathrm{B} \times \mathrm{F}$ & 3.29 & 1 & 10.12 & 車为 \\
\hline $\mathrm{e}$ & 17.56 & 54 & & \\
\hline $\mathrm{T}$ & 36.97 & 63 & & \\
\hline
\end{tabular}

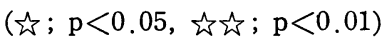

Table 2, b. Means and confidence limits of the factors which are significance in the variance analysis.

\begin{tabular}{|c|c|c|c|c|c|c|}
\hline \multirow{3}{*}{ Factor } & \multicolumn{6}{|c|}{ Level } \\
\hline & \multicolumn{2}{|r|}{1} & \multicolumn{2}{|r|}{2} & \multicolumn{2}{|c|}{ Effect } \\
\hline & Mean & $\begin{array}{c}\text { Confidence } \\
\text { limits }(95 \%)\end{array}$ & Mean & $\begin{array}{c}\text { Confidence } \\
\text { limits }(95 \%)\end{array}$ & Mean & $\begin{array}{l}\text { Confidence } \\
\text { limits }(95 \%)\end{array}$ \\
\hline A & 1.60 & \pm 0.24 & 1.92 & \pm 0.30 & 0.32 & \pm 0.29 \\
\hline B & 1.50 & \pm 0.23 & 2.02 & \pm 0.29 & 0.52 & \pm 0.29 \\
\hline $\mathrm{D}$ & 1.59 & \pm 0.20 & 1.93 & \pm 0.33 & 0.34 & \pm 0.29 \\
\hline $\mathrm{E}$ & 1.61 & \pm 0.20 & 1.92 & \pm 0.33 & 0.31 & \pm 0.29 \\
\hline $\mathrm{F}$ & 1.48 & \pm 0.19 & 2.04 & \pm 0.31 & 0.56 & \pm 0.29 \\
\hline G & 1.60 & \pm 0.19 & 1.92 & \pm 0.33 & 0.32 & \pm 0.29 \\
\hline $\mathrm{B} \times \mathrm{F}$ & 1.99 & \pm 0.33 & 1.53 & \pm 0.19 & 0.46 & \pm 0.29 \\
\hline
\end{tabular}

The factor of frequency is not statistically significant on the first and the second experiment. In our experiment, the vibration was given at the same weighted value to the frequency, which was measured with the quantity weighted by the human sensation. The response of skin temperature to the vibration frequency is considered to be similar to the vibration sensation.

The level $2(6 \mathrm{~kg})$ of the gripping force (D) indicates the more retarded recovery than the level 1. This result is explained as follows. When muscles of the forearm are contracted, the blood flow into the muscles of forearm increases, while the blood flow into the subcutaneous tissue of hand decreases, which is called the vaso-cutaneous reflex. 


\section{VIBRATION EFFECTS ON HAND-ARM-SYSTEM}

When the handle of the vibrating tools was strongly gripped and the vibration was given, blood flow in the forearm muscle increases in comparison with the weaker gripping force. After stop of contraction of the muscles, recovery of the blood flow into the subcutaneous tissue is retarded, so that the recovery of the skin temperature is also delayed. This retardation depends upon the gripping force.

The handle $(\mathrm{E})$ with the big diameter (level $2,5 \mathrm{~cm}$ ) shows larger skin temperature index than that with the small diameter (level $1,3 \mathrm{~cm}$ ). The muscles in the hand-armsystem seem to require larger energy to grip the handle with large diameter at the same strength as to grip that with the small diameter.

On the factor of the order of experiment $(G)$, the result denotes that on the second time (level 2), recovery of the skin temperature is slower than on the first time (level 1). The results of examination at the first time influences that at the second time. That is, the effect of loading of gripping of the handle and the vibration given to the handarm-system has remained after the short rest period.

The time history of the skin temperature of the finger tip for the parameter of vibration amplitude is shown in Fig. 1. Though the difference of curves is small, the

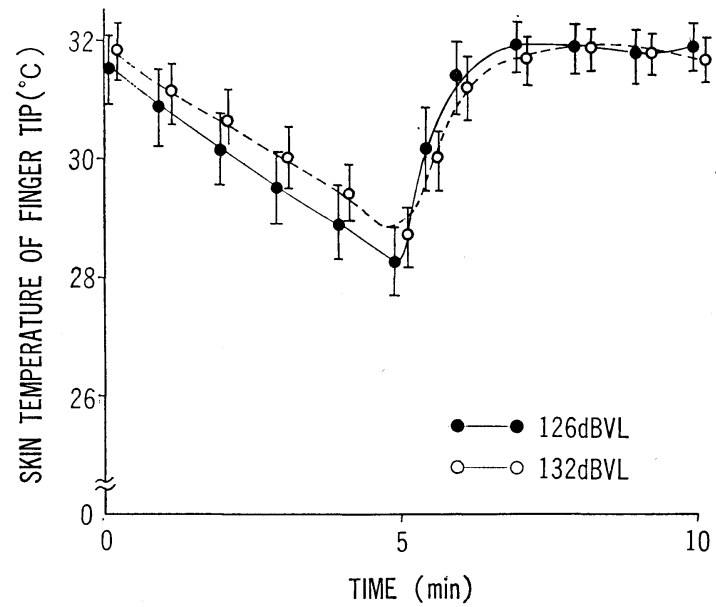

Fig. 1. The effect of vibration magnitude on skin temperature of the finger tip at room temperature $22^{\circ} \mathrm{C}$ in the first experiment.

The observation was carried out on 32 male subjects. The ordinate is the skin temperature of the finger tip and the abscissa is elapsed time. Averages and confidence limits $(95 \%)$ calculated on the factor of vibration magnitude (B) alone were plotted on the curves. From the theory of the experimental design method, when the effects of the factor (B) is calculated, the effects of the other factors in sets of their combinations arranged in the orthogonal array table are cancelled due to the orthogonal relation of that table. 


\section{T. SAKURAI}

skin temperature index is significant in the variance analysis for the vibration levels (B). The time history of the skin temperature for the parameters of the vibration exposure time (A) and the room temperature $(F)$ is plotted in Fig. 2. The data are clearly

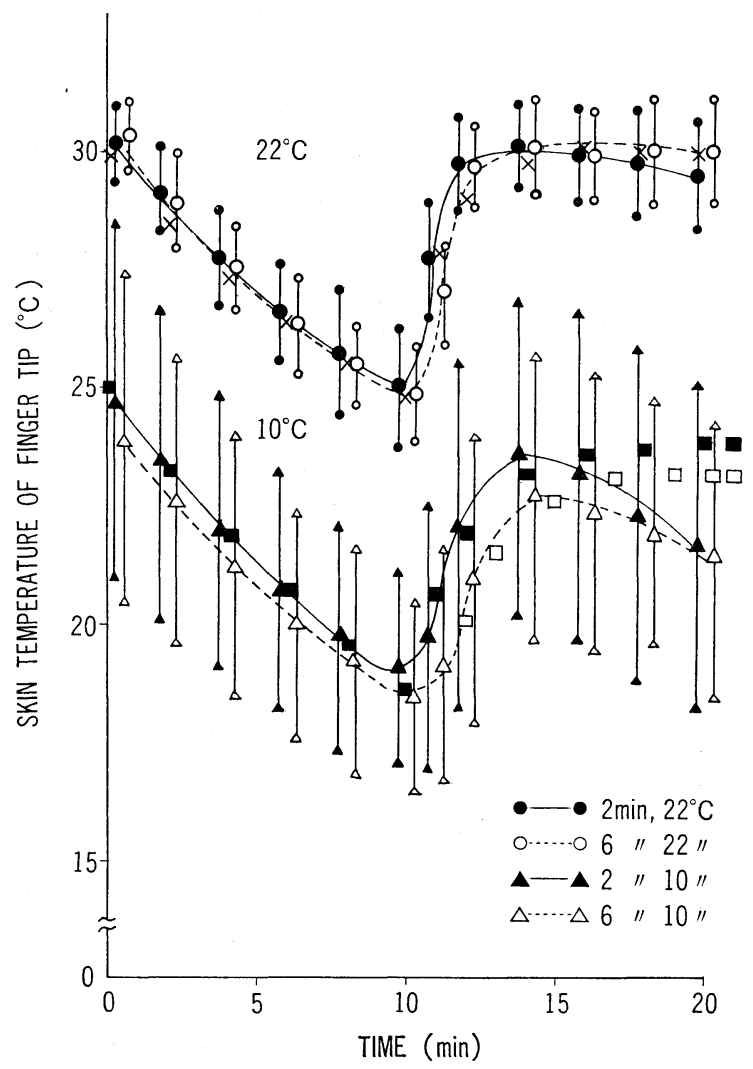

Fig. 2. The effect of the vibration exposure time on the skin temperature of the finger tip at room temperatures of $22^{\circ} \mathrm{C}$ or $10^{\circ} \mathrm{C}$ in the second experiment. The observation was carried out on 16 male subjects. The ordinate is the skin temperature of the finger tip and the abscissa is elapsed time. Averages and confidence limits $(95 \%)$ calculated on the factors of vibration exposure time and room temperature were plotted on the curves. As the effects of the two factors with the two levels are calculated from the combination sets arranged in the orthogonal array table, the four curves are obtained and the effect of the other factors on each curve are cancelled due to their orthogonal relation. The calculated values are shown in the following signs such as, $X$; values calculated from Eq. 2 and Eq. $5, \square$; values calculated from Eq. 3 and Eq. 6 , and $\square$; values calculated from Eq. 8, where Eq. 2; cooling process at $22^{\circ} \mathrm{C}$ for vibration exposure times of 2 or $6 \mathrm{~min}$, Eq. 3; cooling, process at $10^{\circ} \mathrm{C}$ for vibration exposure times of 2 or $6 \mathrm{~min}$, Eq. 5 ; recovery, process at $22^{\circ} \mathrm{C}$ for vibration exposure times of 2 or $6 \mathrm{~min}$, Eq. 6; recovery, process at $10^{\circ} \mathrm{C}$ for vibration exposure time of $2 \mathrm{~min}$ alone, and Eq. 8; recovery process at $10^{\circ} \mathrm{C}$ for vibration exposure times of $6 \mathrm{~min}$ alone. 


\section{VIBRATION EFFECTS ON HAND-ARM-SYSTEM}

separated by the room temperature. The time history of skin temperature at $22^{\circ} \mathrm{C}$ does not indicate the difference between the length of exposure time, which is also not significant in the variance analysis in the case in Fig. 1. On the low room temperature $\left(10^{\circ} \mathrm{C}\right)$, the recovery of the skin temperature is retarded for the longer exposure time of vibration. Namely, the recovery of skin temperature becomes still slower owing to productive effect of the stronger vibration amplitude and the lower room temperature. It is elucidated from this result that the interaction between room temperature $(F)$ and the vibration amplitude (B) exists. The skin temperature index at $10^{\circ} \mathrm{C}$ is also larger. The skin temperature at $10^{\circ} \mathrm{C}$ furthermore, is not recovered to the initial temperature.

On the cooling and the recovery processes of the skin temperature on Figs. 1 and 2, the equation is derived by using the system of first order lag in the automatic-control theory of a heat exchanger. For cooling process,

$$
\theta_{1}=\theta_{r}+\left(\theta_{0}-\theta_{r}\right) e^{-t / t_{0}}
$$

where $\theta_{1}$; temperature of finger tip in the cooling process, $\theta_{r}$; room temperature, $\theta_{0}$; initial temperature of finger tip and $t_{0}$; time constant of this system. If the values of $\theta_{r}=22^{\circ} \mathrm{C}, \theta_{0}=30^{\circ} \mathrm{C}$ (Fig. 2) and $t=t_{0}$ are set, the equation of $\theta_{1}=22+8 e^{-1}=25^{\circ} \mathrm{C}$ is obtained. So, if the time when $\theta_{1}$ becomes at $25^{\circ} \mathrm{C}$ is read out, the time constant is determined, as $t_{0}=10 \mathrm{~min}$. Equation of the cooling process at the room temperature is made as

$$
\theta_{1}=22+8 e^{-t / 10}
$$

In the same way, the equation of the cooling process at $10^{\circ} \mathrm{C}$ as shown in Fig. 2 is formulated as

$$
\theta_{1}=10+15 e^{-t / 18}
$$

On the cooling process, the observed curves are well simulated by these equations as plotted in Fig. 2.

In the recovery process, the equations is derived as

$$
\theta_{2}=\theta_{s}+\left(\theta_{\infty}-\theta_{s}\right)\left(1-e^{-(t-10) / t_{0}}\right)
$$

where $\theta_{s}$; the starting skin temperature in the recovery process, $\theta_{\infty}$; the skin temperature to reach the equilibrium and $t_{0}$; time constant. In Fig. 2 at $22^{\circ} \mathrm{C}$, for example, $\theta_{s}=25^{\circ} \mathrm{C}$, $t=t_{0}+10, t_{0}$ is $1.2 \mathrm{~min}$ as obtained by inspection of the figure. Equation of this process for normal room temperature is made as

$$
\theta_{2}=25+5\left(1-e^{-(t-10) / 1.2}\right)
$$

On the normal room temperature, the equation made agrees with the observed curves in the recovery process as seen in Fig. 2.

For the low room temperature of $10^{\circ} \mathrm{C}$ in Fig. 2, the equation of $2 \mathrm{~min}$ exposure of vibration $\left(\theta_{s}=19^{\circ} \mathrm{C}, t_{0}=2.2 \mathrm{~min}\right)$ is determined as

$$
\theta_{2}=19+5\left(1-e^{-(t-10) / 2.2}\right)
$$




\section{T. SAKURAI}

This simple equation is somewhat contradicted with the data at near the end stage of the experiment in the recovery process, because the system of more than second order lag has to be considered to simulate the process.

To indicate the curve on $6 \mathrm{~min}$ exposure at $10^{\circ} \mathrm{C}$, the dead time component which is observed as $1 \mathrm{~min}$ in Fig. 2, must be supposed. The equation of this curve is

$$
\theta_{2}=\theta_{s}+\left(\theta_{\infty}-\theta_{s}\right)\left(1-e^{-(t-10-L) / t_{0}}\right)
$$

That is,

$$
\theta_{2}=18.5+5\left(1-e^{-(t-11) / 2.2}\right)
$$

This equation also disagrees near the end point in the recovery process.

\section{REFERENCES}

1) Ashe, W.F., Cook, W.T. and Old, J.W. (1962), Arch. Environ. Health, 5, 333

2) Hettinger, T. und Beck, W. (1956), Internat. Z. angew. Physiol. Einschl. Arbeitsphysiol. 16, 250

3) Magos, L. and Okos, G. (1963), Arch. Environ. Health, 7, 402

4) Matoba, T., Kusumoto, H., Omura, H., Kotorii, T., Kuwahara, H. and Takamatsu, M. (1975), Tohoku J. Exp. Med. 115, 385

5) Hettinger, T. (1957), Internat. Z. angew. Physiol. Einschl. Arbeitsphysiol. 16, 472 